\title{
Support Measures to Prevent the Deformation and Failure of a Carbonaceous Mudstone Tunnel
}

\author{
Yongdong Wang $\mathbb{D}^{1},{ }^{1}$ Haitao Jiang, ${ }^{1}$ Xin Yan, ${ }^{2}$ Huiru Liang, ${ }^{3}$ Guoan Li, ${ }^{4}$ Xiao Liu, \\ Hao Peng, ${ }^{5}$ Shantong Wan, ${ }^{1}$ and Wenjun Bai ${ }^{1}$ \\ ${ }^{1}$ School of Highway, Chang'an University, Xi'an 710064, Shaanxi, China \\ ${ }^{2}$ Xinjiang Transportation Planning Survey and Design Institute, Wulumuqi 830006, Xinjiang, China \\ ${ }^{3}$ Guangdong Road and Bridge Construction Development Co., Ltd., Guangzhou 510507, China \\ ${ }^{4}$ Guangdong Communication Planning \& Design Institute Co., Ltd., Guangzhou 510507, China \\ ${ }^{5}$ Guangxi Road and Bridge Engineering Group Co., Ltd., Nanning 530200, China \\ Correspondence should be addressed to Yongdong Wang; wydchdgl@163.com
}

Received 4 July 2020; Revised 6 February 2021; Accepted 20 February 2021; Published 5 March 2021

Academic Editor: Andreas Lampropoulos

Copyright (c) 2021 Yongdong Wang et al. This is an open access article distributed under the Creative Commons Attribution License, which permits unrestricted use, distribution, and reproduction in any medium, provided the original work is properly cited.

\begin{abstract}
A carbonaceous mudstone tunnel is a type of soft rock tunnel. There is little research on the prevention and control measures for the deformation and failure of carbonaceous mudstone tunnels. In this article, we investigated the construction of the Qiguding carbonaceous mudstone tunnel in Meizhou City, Guangdong Province, China. We monitored and analyzed the deformation and stress characteristics of a section under the original support scheme. The monitoring data showed that this section had large peripheral convergence, vault subsidence, steel arch strain, and concrete strain. The deformations exhibited significant differences in the horizontal and vertical directions, eventually resulting in concrete cracking, steel arch bulging, and distortion in the section. The analysis showed that the primary mechanisms for the failure were the softening characteristics of the carbonaceous mudstone, the plastic rheology, and the shear slip of the rock stratum. Based on a comparative analysis and numerical simulation, we proposed a new support measure called the longitudinal rigid enlarged foundation that consists of a steel arch longitudinal connection system and a locking foot anchor pipe system. Several comparative tests were performed at the tunnel site. The results demonstrated the excellent performance and reliability of the proposed support scheme for the deformation control of the carbonaceous mudstone, providing a reference for similar projects.
\end{abstract}

\section{Introduction}

Tunnels have the advantages of shortening the mileage and reducing the slope of highways and are widely used in engineering. Tunnel engineering in China has entered a new stage. The scale of tunnel construction and the construction speed are unprecedented, resulting in increasing challenges. Many tunnels need to be built in environments with poor stratum conditions. Soft rock tunnels are commonly encountered in tunnel construction.

The challenges of constructing rock tunnels in soft rock include large deformation of the surrounding rock, long deformation duration, and a high deformation rate. Scholars have conducted extensive research on the deformation and failure mechanism of rock tunnels in soft rock [1-6] and have proposed and developed support methods for these types of rock tunnels. At present, the research on large deformation support methods of soft rock tunnels can be divided into two categories. The first category is research on support theory, including strong-soft combined support theory, a joint support theory, energy support theory, block sliding support theory, bolt-shotcrete-arc plate support theory, loose circle theory, and uniform support theory of deep surrounding rock [7-12]. Many scholars used various supporting theories to perform research falling into the second category, i.e., the improvement of the supporting 
components. Liu [13] invented a new type of long bolt to achieve "yield support" based on the theory of "strong support and yield pressure." He et al. [14] designed a coupled bolt-net support and a new type of energy-absorbing bolt with large elongation and high constant resistance. Jiao et al. [15] improved the traditional U-shaped steel to support and stabilize a thick and loose coal roadway. Wang et al. [16] developed a constrained concrete (CC) support system and conducted full-scale indoor comparison tests and field comparison tests on the core member CC arch and conventional U-shaped steel arch frame. The results demonstrated the excellent performance of the CC support system to prevent the deformation of the surrounding rock. Wang et al. [17], Chen et al. [18], and Wu et al. [19] developed high compression and low plastic foam concrete and used it as a filling material for the deformation layer between the first and second linings of large-span soft rock tunnels. Low plastic foam concrete can relieve the excessive stress of the secondary lining caused by rock creep, reduce the deformation of the secondary lining, and improve the stability of the tunnel. Kong et al. [20] designed specific measures to deal with dangerous parts of the tunnel. Field-measured data showed that a horseshoe tunnel with six centers and bench excavation prevented large deformations. The "H230 grid steel frame-antisupport limit damper" and an increase in the inverted depth controlled the deformation of the vault and the arch bottom. Tan et al. [21] proposed a combined support system that included a steel mesh, bolt, anchoring cable, shotcrete, compressible U-shaped steel, foamed concrete damping layer, and a fractured rock cushion layer. Wang et al. [22] proposed a new combined support system with a filled wall, shotcrete, grouting cable, prestressed anchor cable, and U-shaped steel support for semicoal-rock roadway reinforcement. Tao et al. [23] investigated the No. 2 inclined shaft of the Muzhailing tunnel and proposed an anchor cable support system with a negative Poisson's ratio (NPR). The system had constant resistance and a high prestressing force and was capable of large deformation to release the surrounding rock pressure.

Significant progress has been made in the research on the large deformation mechanism of soft rock and the deformation control measures, and the theories and techniques have solved many problems related to the support of tunnels in weak surrounding rocks. However, there are many reasons for instability, and the geomechanical mechanisms of the weak surrounding rock are very complicated. The existing research results are not applicable to all deformation conditions of soft rock. Once the key influencing factors change, the results are no longer applicable. Carbonaceous mudstone tunnel is a unique type of soft rock tunnel. The unique, soft characteristics of carbonaceous mudstone represent significant problems for engineers. Research on carbonaceous mudstone has focused on the rock properties [24-27], but few studies investigated the control measures to prevent the deformation and failure of carbonaceous mudstone tunnels.

This paper proposes a new support system-the longitudinal rigid enlarged foundation (LREF) - for the deformation control of a carbonaceous mudstone tunnel. The
Qiguding carbonaceous mudstone tunnel is used as a case study. On-site monitoring data show that the LREF provides excellent performance for controlling the deformation of carbonaceous mudstone tunnels.

\section{Project Background}

2.1. Project Overview. As shown in Figure 1, the Qiguding tunnel is part of the east ring Branch Highway in Meizhou City, Guangdong Province, China, which is a two-way fourlane highway. The lengths of the left and right lanes are $2151 \mathrm{~m}$ and $2164 \mathrm{~m}$, respectively. The tunnel passes through a low mountain and hilly landform area, and the terrain at the entrance is variable. The surrounding rock of the tunnel consists of carbonaceous mudstone and mudstone containing clay minerals. The rock is broken, rock mass folds and flexes are common, and the type of rock is variable. Meizhou City is located at a low latitude close to the South China Sea. Affected by the topography of the mountains and the Pacific Ocean, the precipitation in this area is abundant and high, which results in abundant groundwater in the tunnel site area; there may be water-rich zones in some fracture development areas. According to the principle of the New Austrian method, the tunnel lining was installed using a three-step excavation method, and a composite lining was used. The initial support used a bolt and shotcrete support, the secondary lining was concrete lining, and curved wall lining was used. Table 1 shows the original support measures.

\section{Failure Mechanism Analysis}

\subsection{Monitoring and Analysis of the Surrounding Rock}

3.1.1. Displacement Monitoring of the Surrounding Rock. A convergence instrument and total station were used to monitor the deformation of the surrounding rock in real time to assess the deformation and failure characteristics of the Qiguding carbonaceous mudstone tunnel. Figure 2 shows the settlement of the vault and the convergence of the arch waist, sidewall, and arch foot of section YK11 +465 under the original support scheme. Figure 3 shows a comparison of the accumulated values of the vault settlement of six sections, which are $5 \mathrm{~m}$ apart in each section. The figure shows the following:

(1) The instantaneous deformation was large. Yk11 + 465 section has a large deformation immediately after the upper step excavation, the vault settlement directly reached $20.4 \mathrm{~mm}$, and the horizontal convergence of the arch waist also reached $15.8 \mathrm{~mm}$. With the excavation of the middle step and lower step, the vault and arch waist of the section had a large instantaneous deformation due to disturbance, in which the vault settlement increased by $45.5 \mathrm{~mm}$ instantly and reached $350.8 \mathrm{~mm}$ one week later; the horizontal convergence of the arch waist instantly increased by $23.1 \mathrm{~mm}$ and reached $155.7 \mathrm{~mm}$ one week later. 


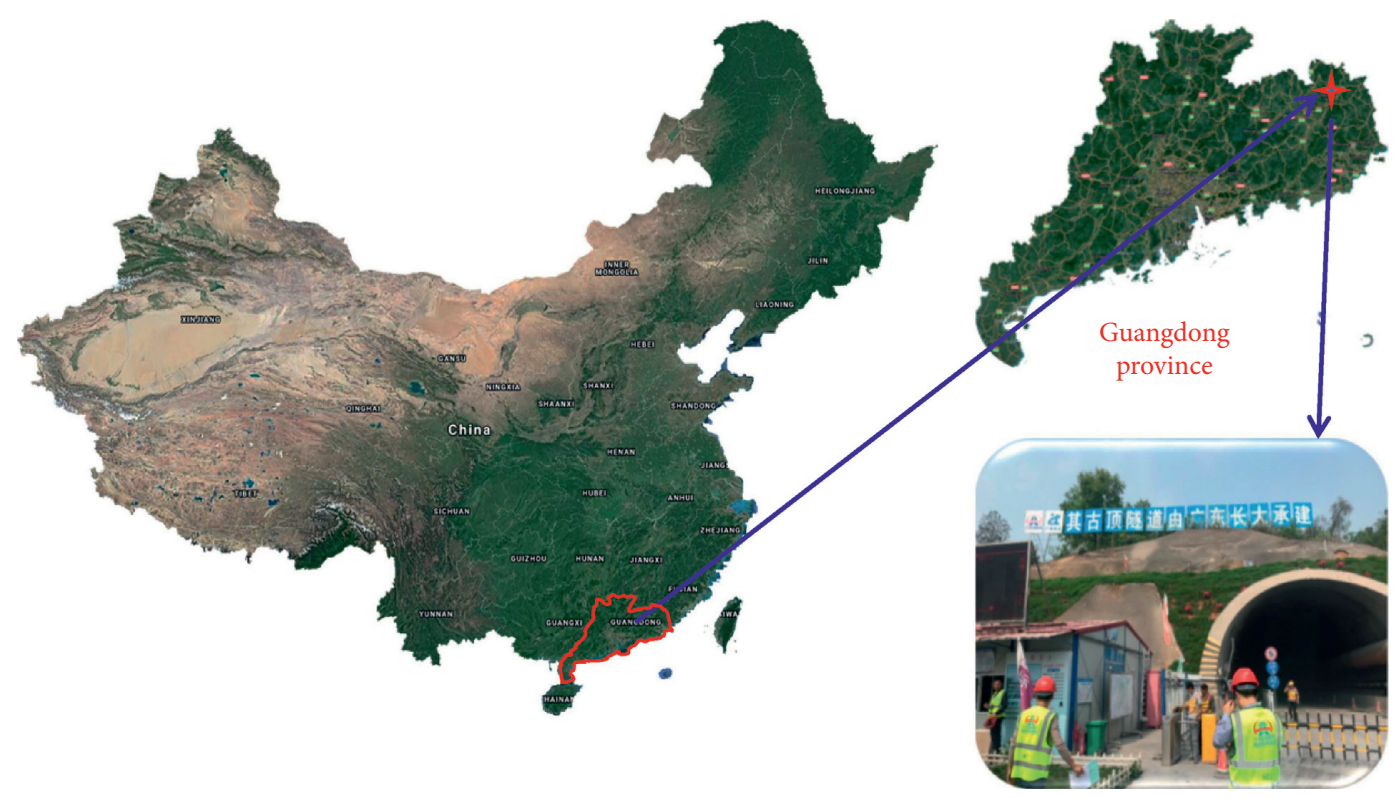

FIgURE 1: The geographical location of the Qiguding tunnel.

TABLE 1: Original support measures.

\begin{tabular}{lc}
\hline Component & Original support measures \\
\hline System anchor & $\Phi 25$ hollow grouting anchor \\
Locking foot anchor & $\Phi 22 \mathrm{~mm}$ roll anchor \\
Longitudinal connection & Rebar channel steel \\
Advanced support & Single-layer small pipe \\
Steel arch & I20a model steel arch \\
\hline
\end{tabular}

(2) The accumulated deformation was large. It could be seen from Figure 2(a) that the accumulated deformation of vault and arch waist was very large after the stability of the YK11 + 465 section, in which the maximum accumulated deformation of vault settlement was $408.02 \mathrm{~mm}$, and the maximum accumulated deformation of arch waist was $199.5 \mathrm{~mm}$. It could be seen from Figure 3 that although the vault settlement of similar sections was different, they were generally larger, and the YK11 480 section with the smallest vault settlement reached $240.7 \mathrm{~mm}$.

(3) The deformation rate fluctuated greatly and lasted for a long time. It can be seen from Figure 2(b) that the deformation rate of the YK11 + 465 section was in a state of constant fluctuation at all times. The deformation rate of the vault reached $15 \mathrm{~mm} / \mathrm{d}$ at the initial stage of excavation and then reached $30 \mathrm{~mm} / \mathrm{d}$ due to disturbance. The horizontal convergence rate of the arch waist reached $8 \mathrm{~mm} / \mathrm{d}$ at the initial stage of excavation and then reached $15 \mathrm{~mm} / \mathrm{d}$ at the maximum. At the same time, Figure 2(b) shows that the deformation of the tunnel lasted a long time after excavation, and the vault and arch waist tended to be stable after 50 days of excavation. Even if the initial support is kept up with the excavation in time, the cross section deformation was still large. This phenomenon of tunnel surrounding rock deformation reflected that the strength of surrounding rock was low and had certain creep characteristics. Even under a very small force, the surrounding rock could continue to deform, and it was difficult to control. In addition, after the blasting excavation of upper, middle, and lower steps, the surrounding rock was disturbed for many times, and the stress redistribution of surrounding rock lasted for a long time, which further aggravated the deformation of surrounding rock and led to concrete cracking and bulging of the arch (as shown in Figures 4(a) and 4(b)).

(4) The accumulated values of the vault settlement of the six sections are high, and there are considerable differences between the results in Figure 3, indicating uneven longitudinal settlement in this section of the tunnel, which resulted in circumferential cracks in the tunnel (as shown in Figure 4(c)), or may lead to collapse.

3.1.2. Stress Monitoring of the Support Structure. We performed monitoring of the stress of the ZK11 + 430 section under the original support scheme using a pressure box and vibrating wire strain gauge. The layout of the measuring points and field installation are shown in Figures 5 and 6 , respectively. Figures 7-9 show the pressure of the surrounding rock, the strain of the steel arch, and the strain of the concrete, respectively, in section ZK11 + 430. The figure shows the following:

(1) After the excavation of the upper stage, the pressure of the arch crown reaches 1.23 MPa, that of the right arch waist is $0.74 \mathrm{MPa}$, and that of the left arch waist is $0.33 \mathrm{MPa}$. After the excavation of the middle and lower steps, the surrounding rock pressure of the arch crown and the arch waist slightly increases, but 


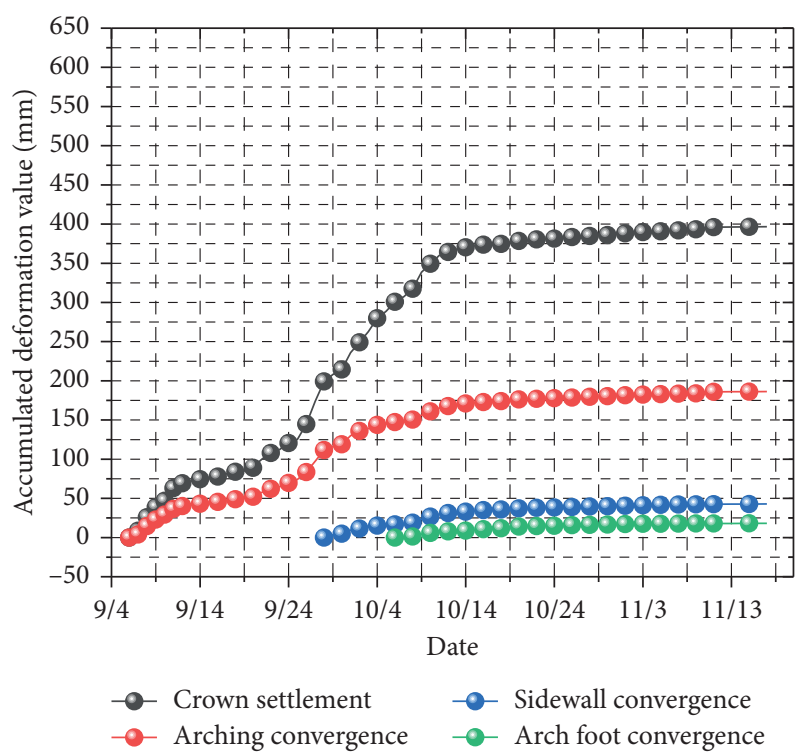

(a)

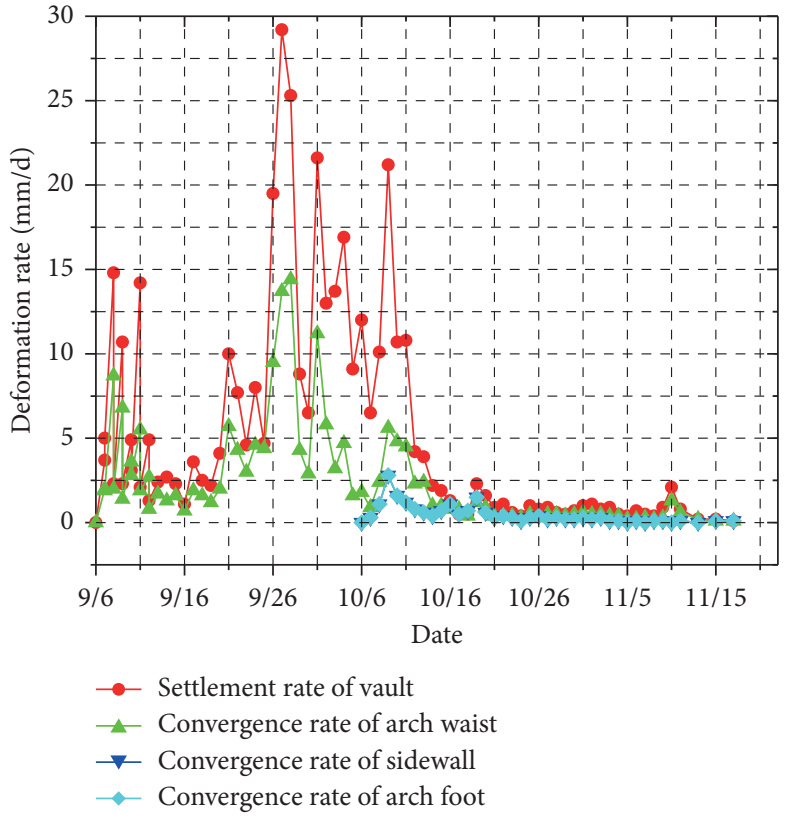

(b)

FIGURE 2: A time-dependent displacement curve of rock mass of section YK11 + 465 in Qiguding tunnel: (a) cumulative value of deformation; (b) rate of deformation.

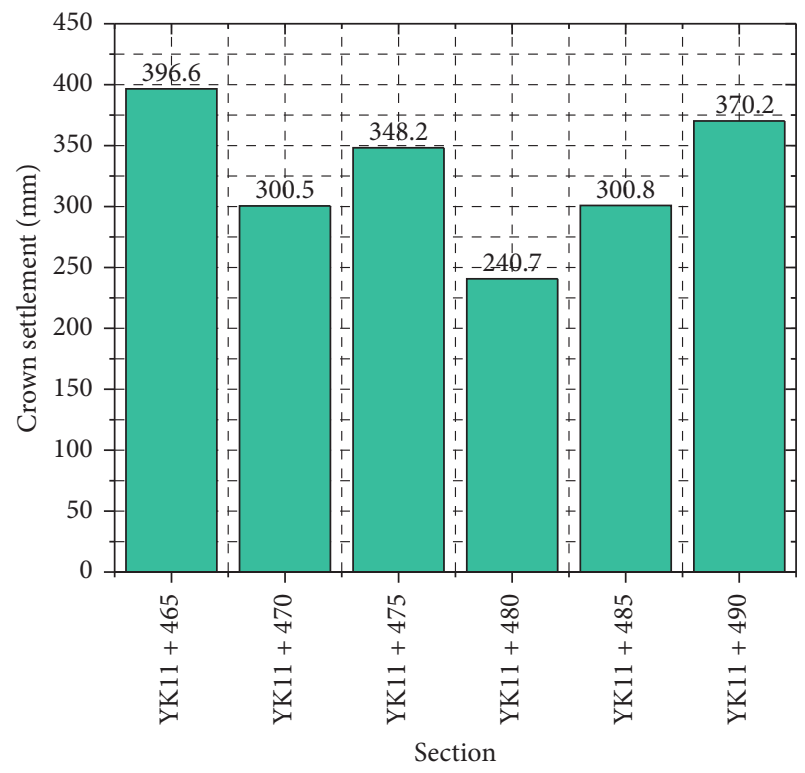

FIgURE 3: Comparison of the vault settlement of 6 sections (each section is 5 meters apart).

the pressure generally decreases and finally stabilizes. The pressure of the sidewall and arch foot is small, the minimum pressure is $0.001 \mathrm{MPa}$, and the maximum pressure is $0.005 \mathrm{MPa}$. When the surrounding rock is broken, the initial stress release after the excavation of the upper stage is large, which may cause the collapse of the top part of the tunnel.

(2) The strain of the steel arch is larger at the crown and the waist than in the other locations. The maximum compressive stress of the steel arch crown is $4080 \mu \varepsilon$, that of the right arch waist is $3200 \mu \varepsilon$, and that of the left arch waist is $2700 \mu \varepsilon$. The deformation of the steel arch frame at the crown and the waist increases as the upper, middle, and lower steps are excavated. The stability value indicates that the steel arch frame at the vault and arch waist may be damaged.

(3) The strain of the concrete is highest at the vault $(2870 \mu \varepsilon)$, followed by the right arch waist and the right sidewall, which are $1540 \mu \varepsilon$ and $1270 \mu \varepsilon$, respectively. The deformation of these three parts is greater than that of the other locations. The concrete strains in each time period indicate that the strain of the tunnel vault and the concrete on the right side increases as the excavation process proceeds, demonstrating that the right side of the tunnel is prone to cracks.

3.2. Softening Characteristics and Plastic Rheology of Carbonaceous Mudstone. Due to the influence of a strong structure and weathering before the tunnel excavation, the rock mass is loose and broken (as shown in Figure 10). The rock is dense and dry under the action of high confining pressure, exhibiting strength and stability. However, after the excavation of the tunnel, the stress of the surrounding rock is rapidly redistributed, and the original closed structural plane in the rock mass opens and slips, causing cracking of the rock mass. In addition, due to the change in the stress state and the fragmentation of the rock mass, the fissure water, which was originally sealed in the bedrock, expands rapidly due to the open structural plane. The water infiltrates into the original dry rock structural plane, softening and 


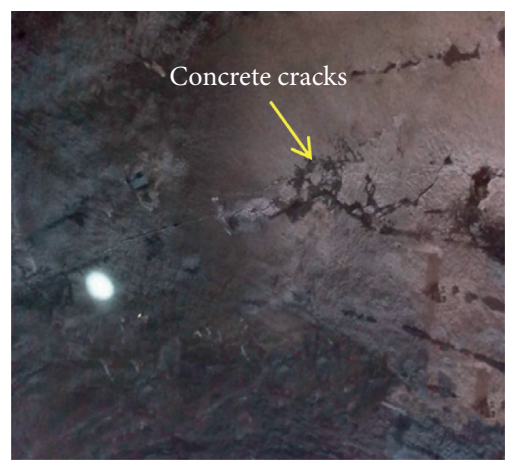

(a)

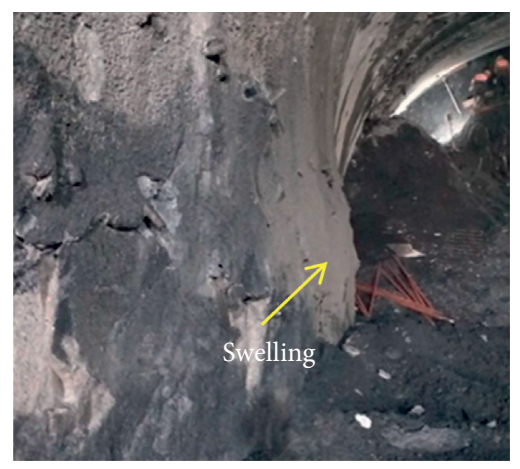

(b)

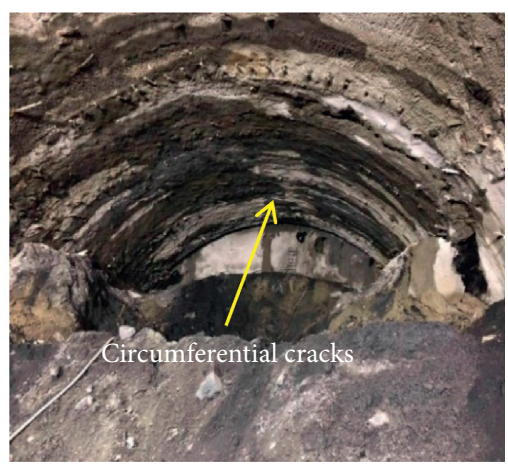

(c)

FIgURE 4: Tunnel deformations and destruction: (a) concrete cracks; (b) arch swelling; (c) circumferential cracks due to uneven longitudinal settlement.

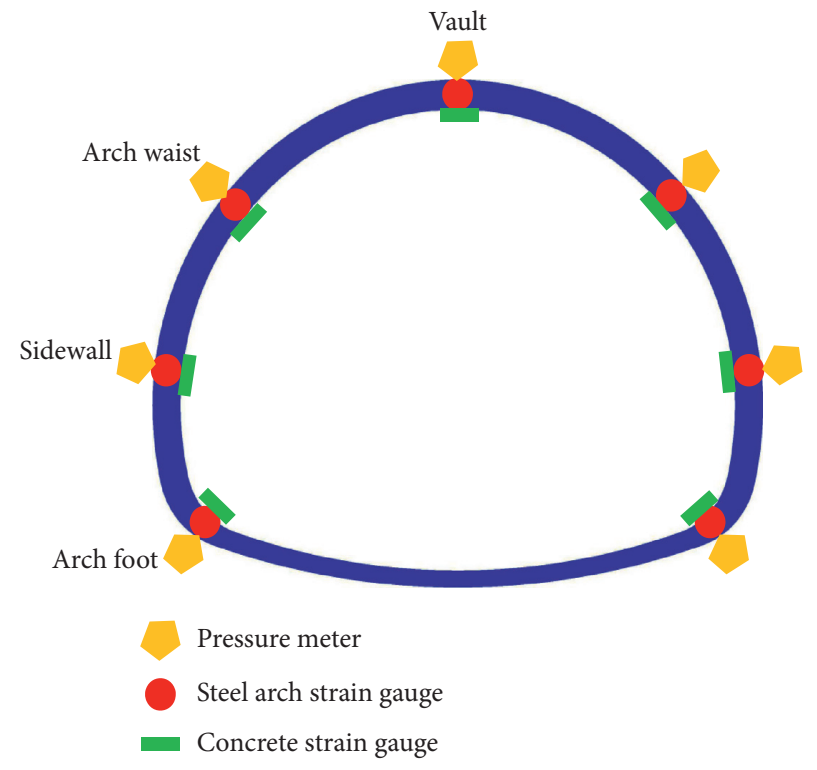

Figure 5: Layout of the measuring points in tunnel section.

expanding the rock mass. After the excavation of the tunnel, because the rock mass is loose and broken, the surrounding rock loses its self-supporting capacity. At this time, a plastic area develops and continues to expand over time. The rock deformation enters the plastic flow stage, and high pressure of the surrounding rock will be generated under the initial support. As the plastic zone expands, the pressure of the surrounding rock acting on the initial support also increases. When the initial support reaches the yield strength limit, yield deformation occurs, resulting in excessive displacement around the tunnel and even deformation failure.

3.3. Shear Slip Deformation of the Rock Stratum. The carbonaceous mudstone section of the Qiguding tunnel is a thin-layer rock mass, and the cohesion between the mudstone layers is weak. The deformation and failure mechanism of the tunnel with a layered rock mass is closely related to the layered structure of the rock mass and manifests in the bedding sliding deformation of the rock mass along the layers after excavation and unloading. The surrounding rock of the Qiguding carbonaceous mudstone tunnel has an inclined thin-layer structure (Figure 11). Bedding is developed, and the rock mass is broken. After the excavation and unloading of the rock mass, the rock will slide along the existing structural plane. Different sliding displacements will produce different degrees of stress on the tunnel lining, causing local damage, which is primarily manifested in large differences in the settlement value in the same section of the tunnel. In addition, due to the lack of integrity and rigidity of the longitudinal connection of the tunnel steel arch frame, the surrounding rock will also slip along the layer in the longitudinal direction, resulting in uneven longitudinal deformation of the surrounding rock (Figure 12). Multiple arches are sheared and twisted as a result.

\section{Longitudinal Rigid Enlarged Foundation Support}

At present, a common support method for carbonaceous mudstone tunnels is to strengthen the original support structure, such as providing double-layer support or increasing the strength of the bolts and the layout density. These reinforcement measures may cause material waste and do not solve the problem of the large difference in the transverse convergence and the uneven settlement of the longitudinal vault well in this project. Therefore, we designed a new support measure called the LREF, which includes the optimization of the longitudinal connection of the steel arch frame and the locking foot anchor pipe.

\subsection{Longitudinal Connection of the Steel Arch}

4.1.1. Common Longitudinal Connection Methods of the Steel Arch. The longitudinal connection of the steel arch is a crucial connection between the adjacent steel arch and an important structure to ensure the integrity of the support system. It not only improves the lateral resistance of the support structure but also the longitudinal integrity of the support structure. Common longitudinal connection methods of the steel arch frame include a rebar connection and channel steel connection. 


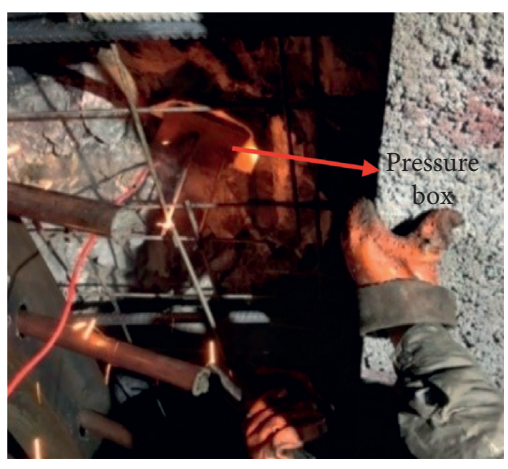

(a)

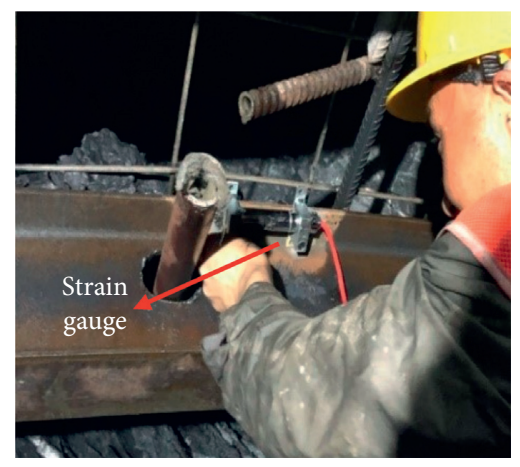

(b)

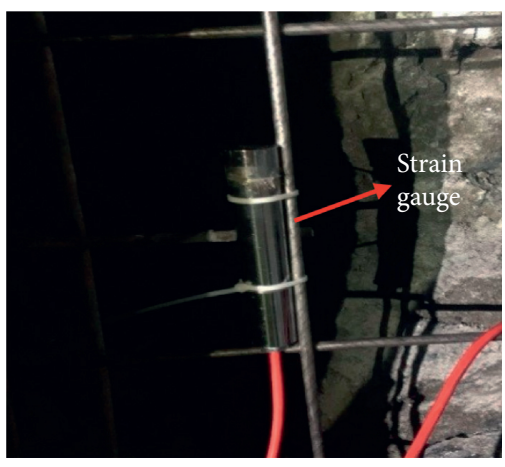

(c)

FIGURE 6: Field installation of the experimental devices: (a) pressure box; (b) steel arch strain gauge; (c) concrete strain gauge.

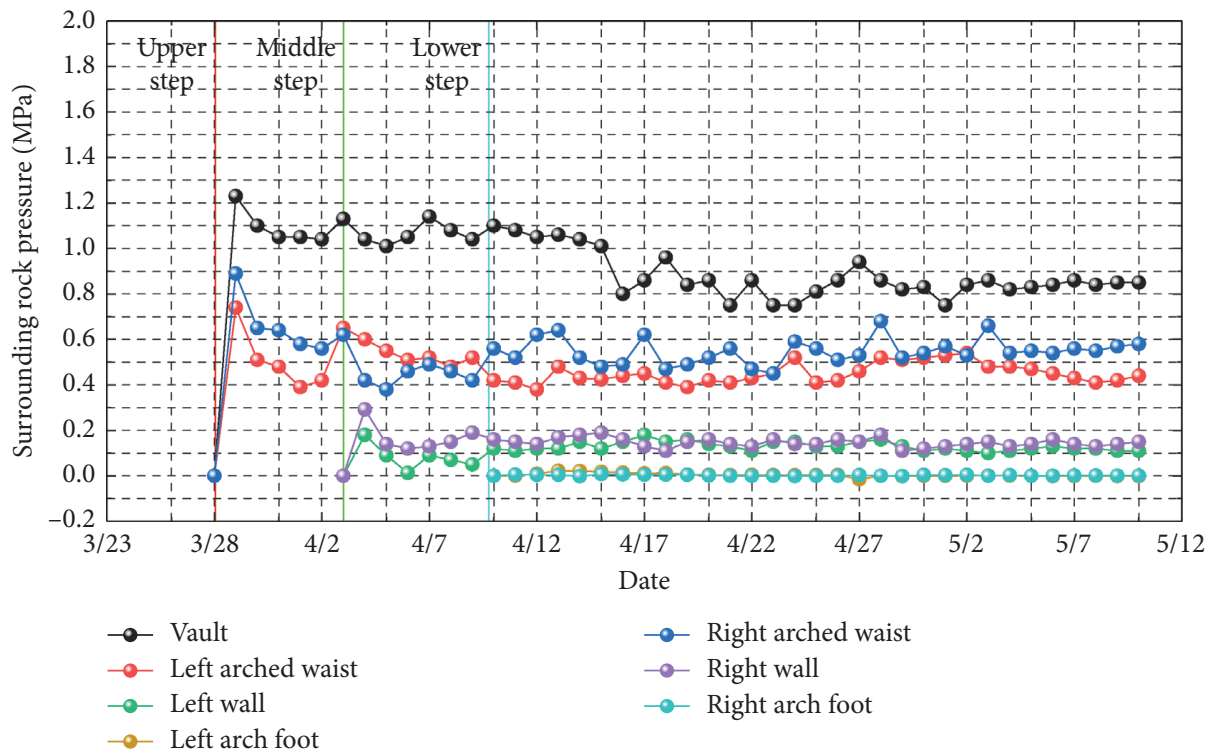

Figure 7: Pressure of the surrounding rock in section ZK11 +430 .

The rebar connection is the most common method for the longitudinal connection of the steel arch (Figure 13(a)). The rebar is generally welded to the inside of two adjacent steel arches, which are separated by a distance and perpendicular to the interface of the two steel arches. The rebar and concrete have good bonding performance, which increases the longitudinal integrity of the steel arch. However, the connection between the rebar and the steel arch is a point connection, with low holding capacity, and the strength of the rebar is limited. Under a large and uneven force, the rebar is prone to twisting and damage, resulting in the failure of the longitudinal connection rebar.

The longitudinal connection that uses channel steel is an important connection mode in soft rock tunnels. The channel steel is generally welded inside the adjacent steel arch (as shown in Figure 13(b)). The I-beams can be located at a distance from each other, or they can be located in the lower part of the section. Because the longitudinal connection of the channel steel uses cross section welding, the contact surface with the steel arch is larger than that of the threaded steel, and the rigidity and strength of the channel steel are greater than those of the threaded steel. Thus, the support performance of the channel steel connection is better than that of the rebar connection in soft rock tunnels. However, in construction, it is difficult to ensure that the channel steel is connected in a straight line; if this is not performed correctly, the support performance of the channel steel connection in the longitudinal direction is significantly reduced, and the longitudinal settlement is uneven.

4.1.2. New Longitudinal Connection of the Steel Arch. We propose a new longitudinal connection system to address the problems of the Qiguding tunnel. The system includes the longitudinal connection plate, bolt, longitudinal lap plate, and steel arch frame. The LREF is located at the locked feet of the upper, middle, and lower steps of 


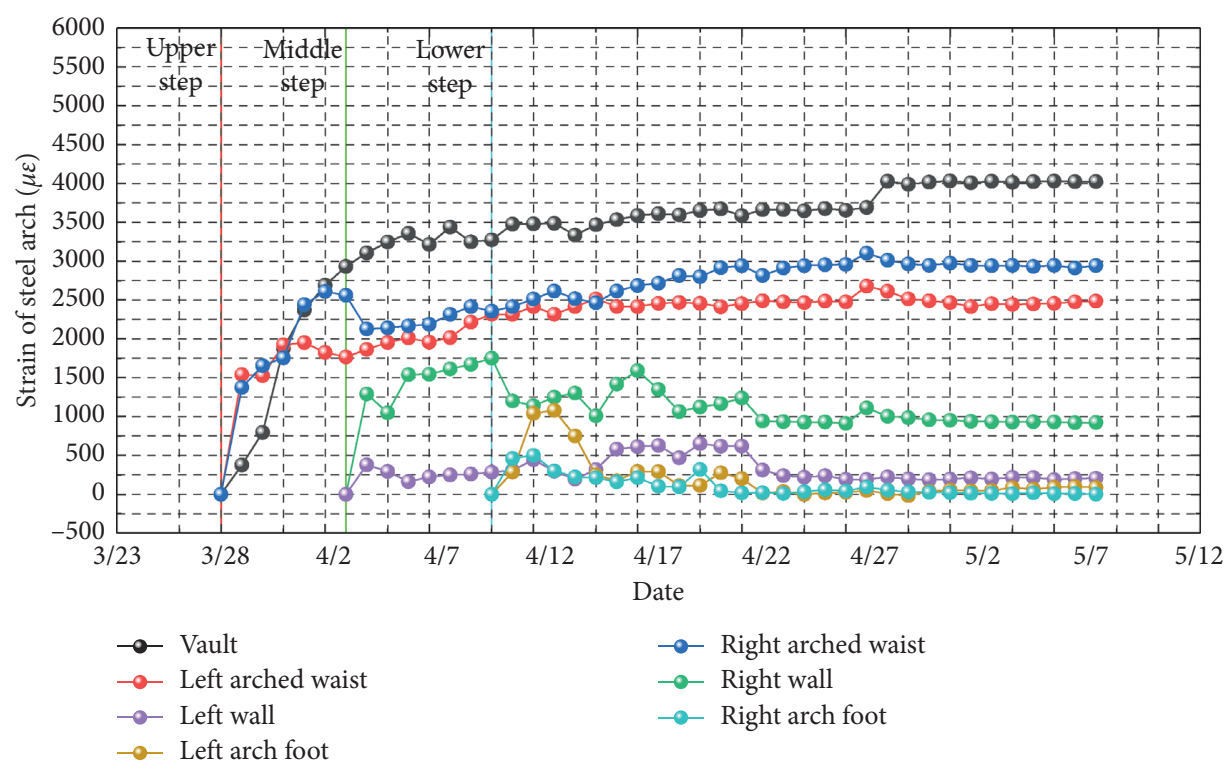

FIGURE 8: Strain of the steel arch in section ZK11 +430.

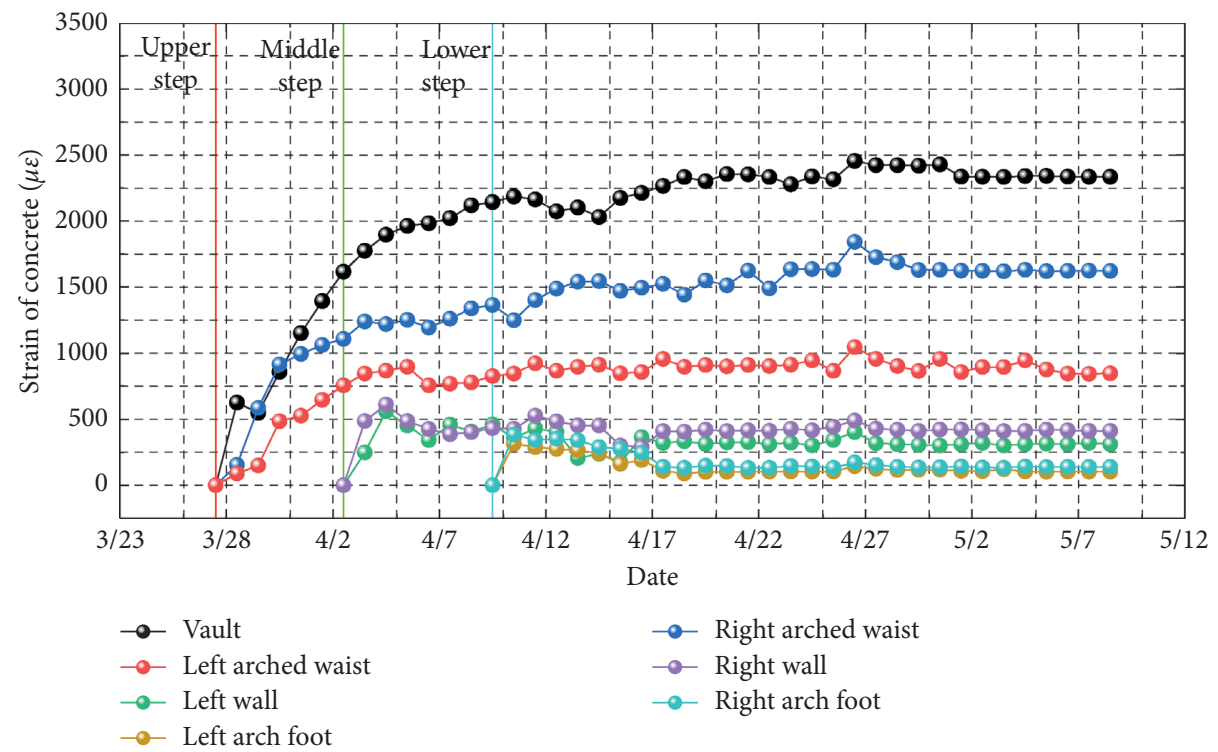

FIgURE 9: Strain of the concrete in section ZK11 + 430.

the steel arch. The longitudinal connection plate is anchored to the steel arch lap plate, and the two longitudinal connection plates are anchored to the lap plate in the center of the two steel arch frames. Figures 14(a)-14(c) show the schematic diagram, the three-dimensional schematic diagram, and site assembly photos of the new longitudinal connection system.

The figures show that the longitudinal connection plate in the rigid expansion foundation not only connects the two adjacent steel arches in the longitudinal direction but also connects the I-steel of the steel arch in the transverse direction. This configuration strengthens the weak area of the steel arch, i.e., the I-beam lap plate, and maintains the longitudinal connection of the steel arch in a straight line, significantly increasing the strength, rigidity, and integrity of the longitudinal connection.

4.2. Optimization of the Locking Foot Anchor. The main function of the locking foot anchor is to limit the rigid body displacement of the steel arch frame so that it can bear the pressure of the surrounding rock deformation as early as possible. However, different angles and lengths of locking foot anchor pipes have different effects on the locking of steel arches. FLAC3D numerical software is used to simulate the support role of the angle-locking anchor pipe and to determine the optimal combination of the parameters of the angle-locked anchor pipe. 


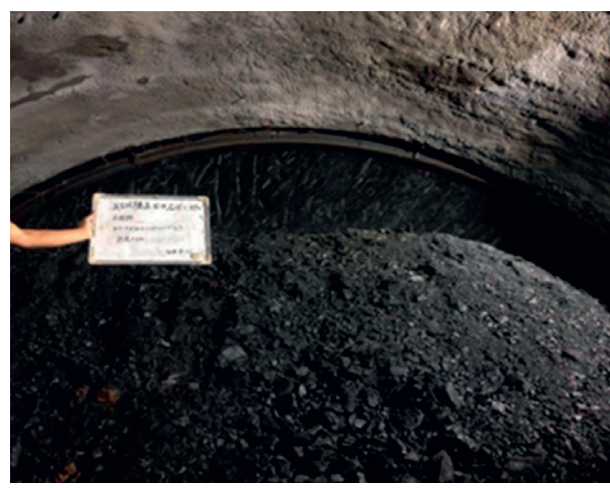

(a)

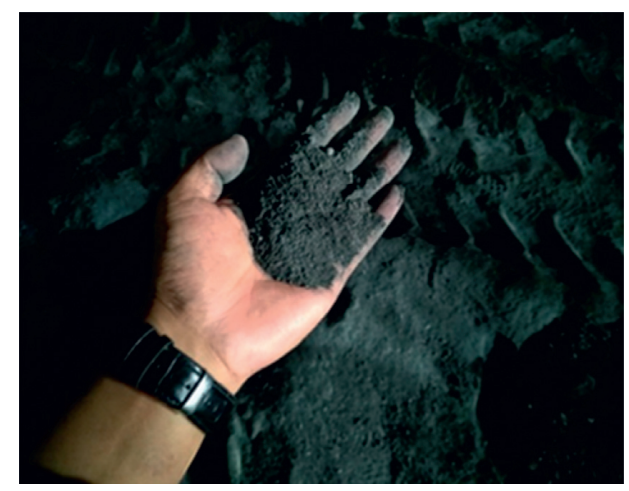

(b)

FIGURE 10: Loose broken rock: (a) granular carbonaceous mudstone; (b) powdery carbonaceous mudstone.

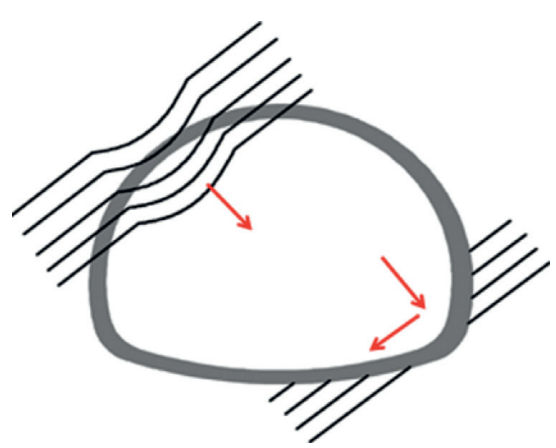

FIGURE 11: Transverse shear slip deformation (arrow indicates the direction of slip).

4.2.1. Modeling and Simulation Process. First, a two-dimensional model of the Qiguding tunnel is established to simulate the excavation and support; the length $\times$ height of the model is $70 \mathrm{~m} \times 50 \mathrm{~m}$. Different parts of the model have different grid densities to improve the simulation speed and accuracy. The soil mesh in the tunnel excavation contour and equivalent reinforcement circle is dense, and the mesh in the other areas is sparse. The mesh size of the anchor rod is 0.1 M. In the analysis of the effect of the length or angle of the anchor pipe on the support performance, the other parameters of the concrete and the reinforced composite soil are held constant. The support parameters in the simulation are listed in Table 2.

This simulation assumed a three-bench excavation method. The simulation process is shown in Figure 15. Six different working conditions with different values of the length and angle of the anchor pipe were investigated in the simulation (Table 3), and orthogonal simulation was performed, which included 46656 conditions.

4.2.2. Comparative Analysis of the Simulation Results. The simulation results of the different working conditions (lengths and angles) of the locking foot anchor are shown in Figure 16. The following was observed:

(1) For the same length of the anchor pipe, as the anchor angle increases, the vault settlement initially decreases and then increases. For the same locking angle of the anchor pipe, as the length of the anchor pipe increases, the vault subsidence first decreases and then remains the same. When the length of the anchor pipe is less than or equal to $3 \mathrm{~m}$, the settlement of the vault decreases with an increase in the length. When the length of the anchor pipe is more than $3.5 \mathrm{~m}$, the settlement deformation is unchanged at different angles, and the control effect on the settlement of the vault is the same.

(2) For the same length of the anchor pipe, as the angle increases, the peripheral convergence first decreases and then increases. The peripheral convergence deformation is smallest at $35^{\circ}$ and largest at $10^{\circ}$. For the same locking angle of the anchor pipe, when the length of the anchor pipe is less than $3 \mathrm{~m}$, the peripheral convergence decreases with the increase in the angle. When the length of the anchor pipe is more than $3 \mathrm{~m}$, the peripheral convergence is the same at the same angle.

(3) As the angle of the anchor pipe increases, the maximum stress value in the $Y$-direction of the vault first increases and then stabilizes. As the length of the anchor pipe increases, the maximum stress in the $Y$ direction of the vault first increases and then decreases. The final maximum stress in the $Y$-direction is the same for the anchor pipes with lengths of $3 \mathrm{~m}$ and $3.5 \mathrm{~m}$, and this value is higher than that of the other lengths of the anchor pipe. The reason is that the length of the anchor pipe has the largest influence on the transverse support and end support. However, the lateral support performance of the pipes with less than $3 \mathrm{~m}$ is poor, as is the end support performance of the pipes that are longer than $3.5 \mathrm{~m}$.

(4) As the angle increases, the rate of change in the stress in the $X$-direction of the arch foot is low. As the length of the anchor pipe increases, the stress in the $X$-direction increases. When the length of the anchor pipe is more than $3.5 \mathrm{~m}$, the rock mass in the reinforcement circle is disturbed, the pressure on the bearing arch is increased, the deformation of the steel 


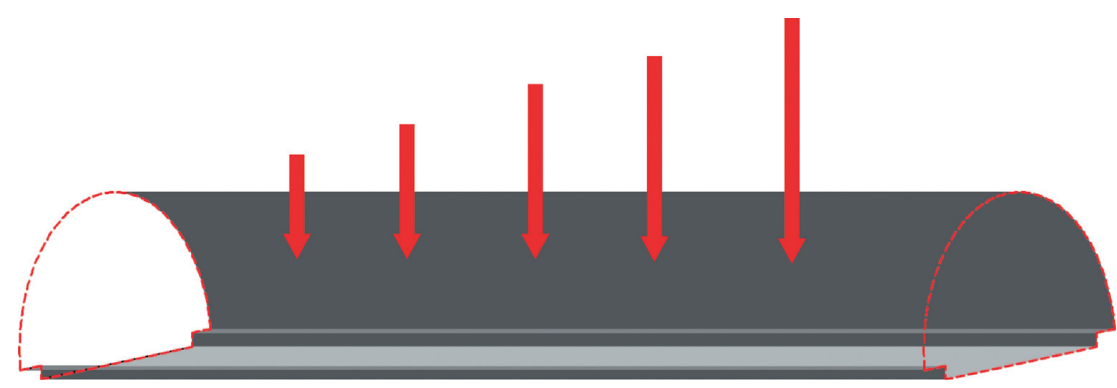

FIGURE 12: Longitudinal shear slip deformation (arrow indicates the direction of slip).

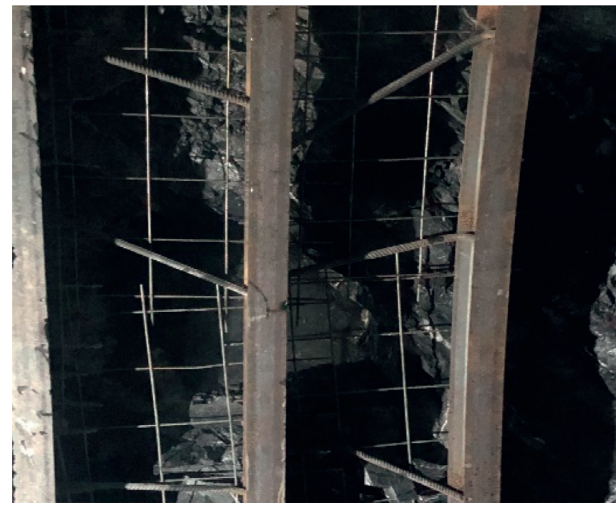

(a)

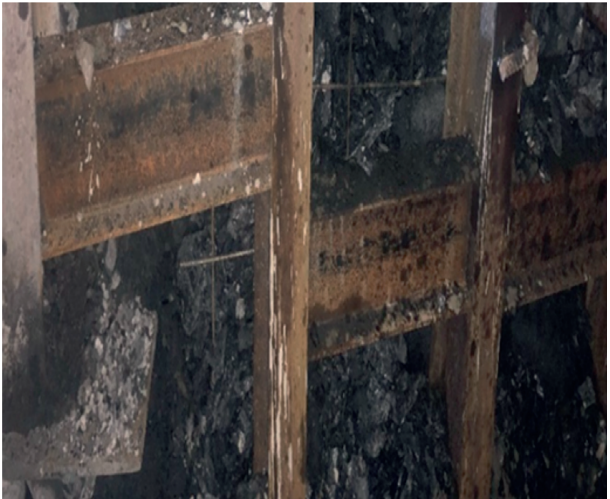

(b)

FIGURE 13: Common longitudinal connection methods of the steel arch: (a) longitudinal connection of the rebar; (b) longitudinal connection of the channel steel.

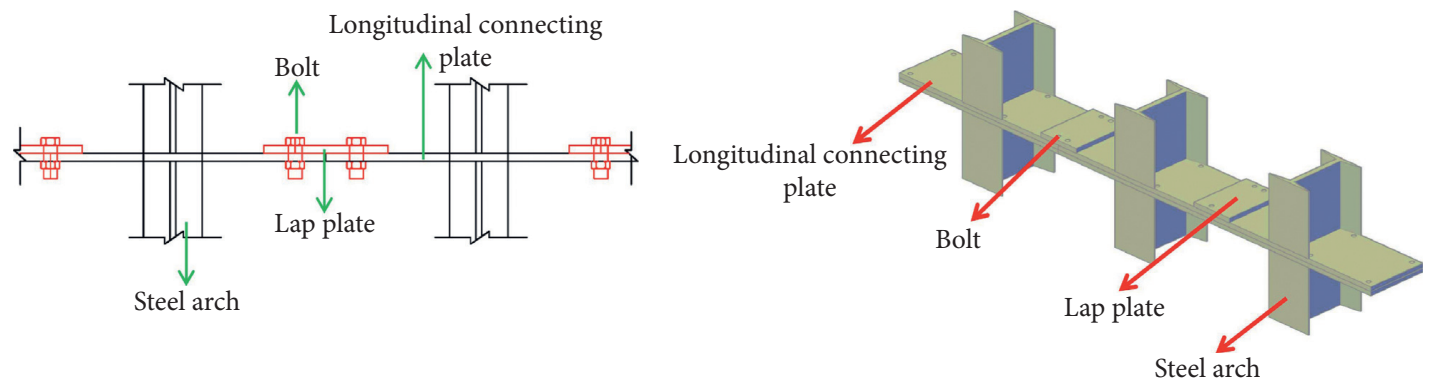

(a)

(b)

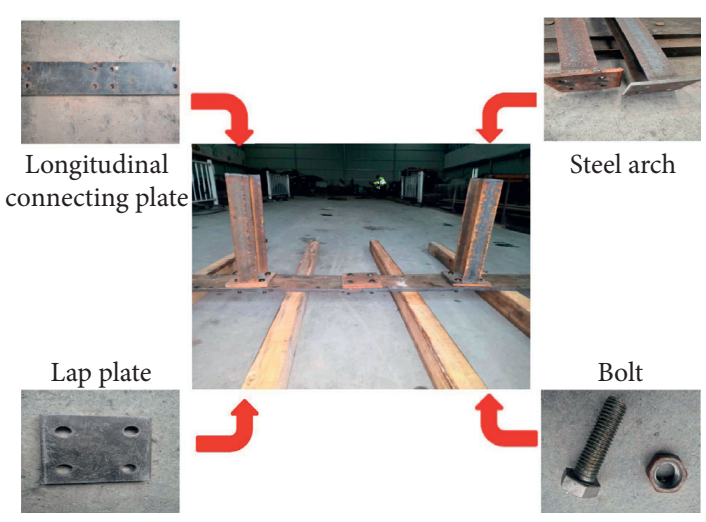

(c)

FIgURE 14: New longitudinal connection system: (a) schematic diagram of the new longitudinal connection system; (b) three-dimensional drawing of the new longitudinal connection system; (c) site assembly photos of the new longitudinal connection system. 
TABLE 2: Support parameters.

\begin{tabular}{lccc}
\hline Material type & Modulus of elasticity $(\mathrm{GPa})$ & Density $\left(\mathrm{kg} / \mathrm{m}^{3}\right)$ & Poisson's ratio \\
\hline Steel arch equivalent shotcrete & 26.64 & 2408 & 0.2 \\
Lock foot anchor pipe & 205 & 3250 & 0.3 \\
\hline
\end{tabular}

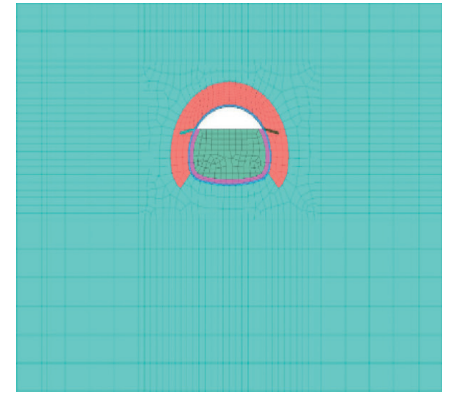

(a)

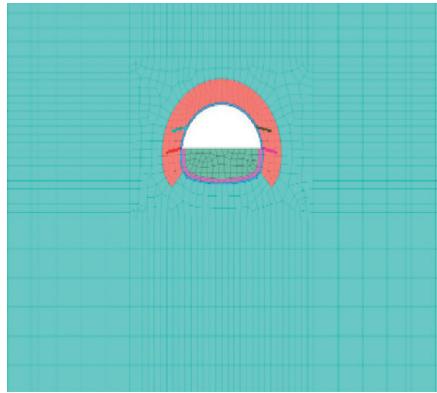

(b)

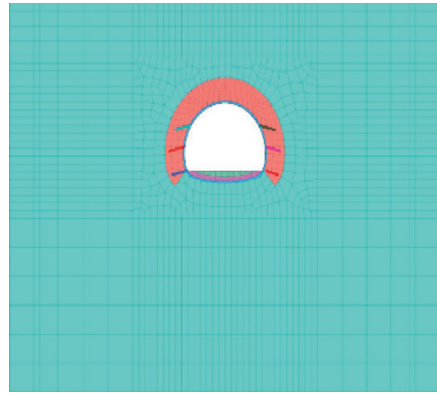

(c)

FIGURE 15: Simulation process: (a) excavation of the above step; (b) middle step excavation; (c) installation of the concrete strain gauge.

TABLE 3: Working conditions of the locking foot anchor.

\begin{tabular}{lccccc}
\hline Parameter type & \multicolumn{5}{c}{ Working condition } \\
\hline Length $(\mathrm{m})$ & 2.5 & 2.8 & 3.0 & 3.5 & 4.0 \\
Angle $\left(^{\circ}\right)$ & 10 & 15 & 20 & 30 & 4.5 \\
\hline
\end{tabular}

arch increases, and the stress in the $X$-direction between the surrounding rock and the steel arch decreases. Therefore, as the angle of the anchor pipe increases, the area of disturbance increases or decreases, the deformation of the steel arch decreases, and the pressure between the surrounding rock and the support increases.

A numerical simulation of the locking foot anchor support is conducted. The analysis of the peripheral convergence, vault subsidence, and steel arch support pressure for the different parameters indicated that the optimal setting angle and length of the angle-locked anchor pipe in the carbonaceous mudstone were $35^{\circ}$ and $3.5 \mathrm{~m}$, respectively.

In summary, we described the LREF using a comparative analysis and determined the optimal parameters of the anchor pipe using a simulation.

\section{Performance of the Support Measures}

We conducted a field test of the LREF in the Qiguding carbonaceous mudstone tunnel, recorded and analyzed the test data, and evaluated the reliability and applicability of the tunnel deformation and failure support measures.

5.1. Test Plan. Four test sections were selected in the Qiguding tunnel; the support methods of the test sections are shown in Table 4 . A vibrating wire strain gauge was used to monitor the strain of the steel arch and concrete of the section, and a convergence instrument and total station were used to monitor the peripheral convergence and vault settlement of the section. Figure 17 and Table 5 show the layout and monitoring plan of the instruments on-site.

5.2. Results and Discussion. Figures 18 and 19 show the changes in the strain of the steel arch and concrete of sections 1, 2, and 3. Figures 20 and 21 show the cumulative values of the settlement of the vault and the convergence around the upper steps after sections 1, 2, 3, and 4 were stabilized. The following is observed in the figures:

(1) After the excavation of the upper step, the three sections of the steel arch frame produce significant strain, indicating that the top stress release is faster after the disturbance of the tunnel excavation. As a result, the support structure bears more pressure after the support of the upper step. After the excavation of the middle and lower steps, the surrounding rock is disturbed again, and the strain of the steel arch in sections 1 and 2 increases, whereas the strain of the steel arch in section 3 decreases and only increases slightly on the left sidewall. The reason is that the surrounding rock is more broken on the left side of the wall than the right side in section 3 . Over time, the strain in the three sections of the steel arch decreases until it is stable. After stabilization, the strain values of the three sections of the steel arch frame are in the following order: section $1>$ section $2>$ section 3 . 


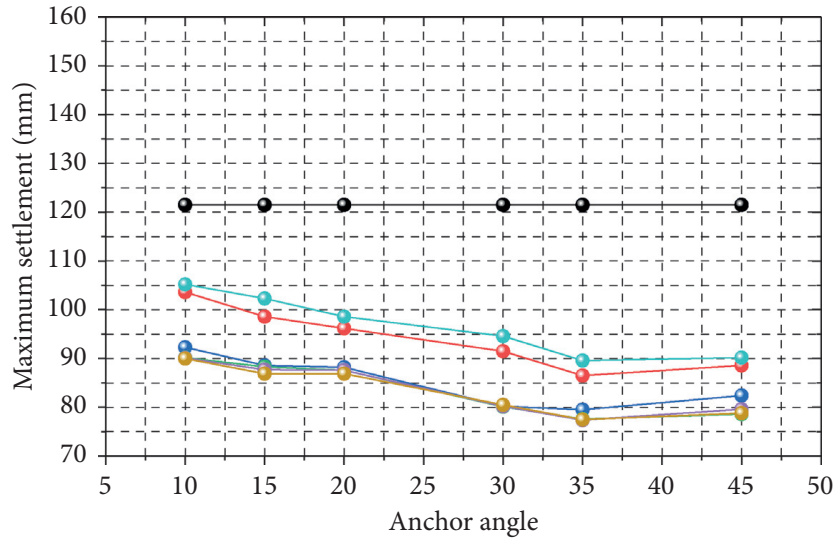

Length of locking foot anchor:

$$
\begin{aligned}
& \multimap-2.5 \mathrm{~m} \\
& \multimap-4.5 \mathrm{~m} \\
& \multimap-4.0 \mathrm{~m} \\
& \multimap-3.5 \mathrm{~m}
\end{aligned}
$$

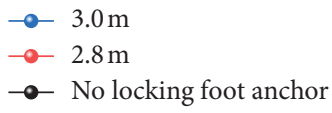

(a)

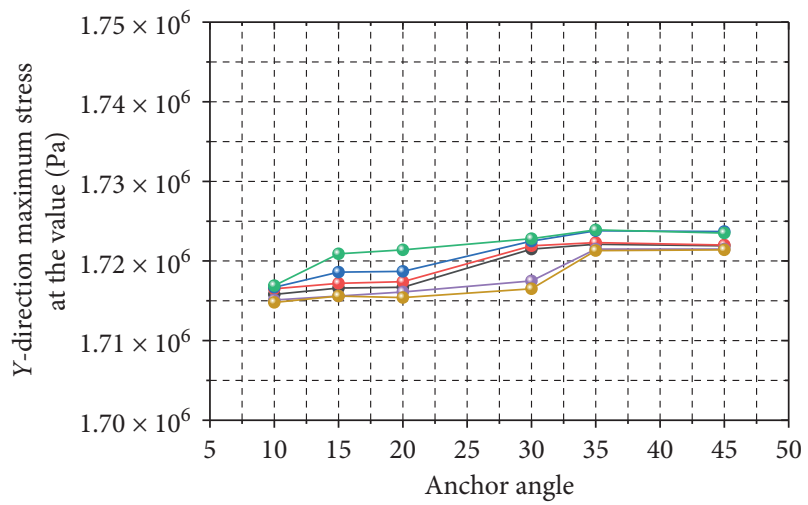

Length of locking foot anchor:

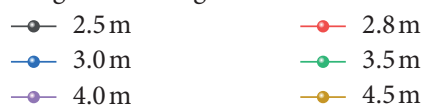

(c)

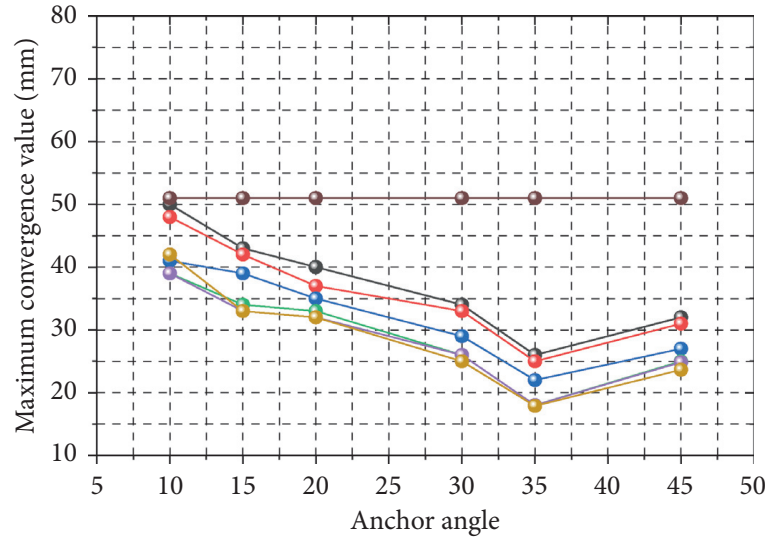

Length of locking foot anchor:

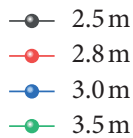

$\rightarrow-4.0 \mathrm{~m}$

$\multimap-4.5 \mathrm{~m}$

$\multimap$ No locking foot anchor

(b)

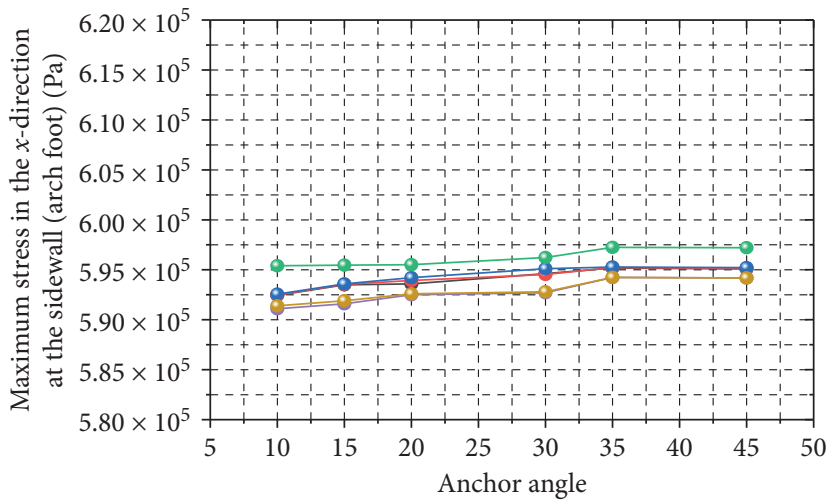

Length of locking foot anchor:

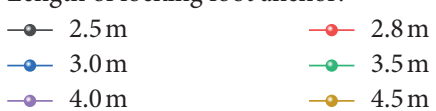

(d)

FiguRE 16: Simulation result graphs: (a) the maximum settlement for different anchor pipe lengths; (b) the maximum convergence for different

\begin{tabular}{|c|c|c|c|c|}
\hline $\begin{array}{l}\text { Section } \\
\text { number }\end{array}$ & $\begin{array}{l}\text { Mileage } \\
\text { station }\end{array}$ & Longitudinal connection mode & $\begin{array}{l}\text { Lock foot anchor } \\
\text { pipe }\end{array}$ & Notes \\
\hline 1 & $\mathrm{Zk} 10+340$ & \multirow{4}{*}{$\begin{array}{c}\text { Rebar connection } \\
\text { Channel steel connection } \\
\text { New longitudinal connection } \\
\text { system } \\
\text { New longitudinal connection } \\
\text { system }\end{array}$} & Installed & \multirow{4}{*}{$\begin{array}{l}\text { Locking foot anchor pipe parameters: } 3.5 \mathrm{~m} \text {, } \\
\qquad 35^{\circ}\end{array}$} \\
\hline 2 & $\mathrm{Zk} 10+350$ & & Installed & \\
\hline 3 & $\mathrm{Zk} 10+360$ & & Installed & \\
\hline 4 & $\mathrm{Zk} 10+370$ & & Not installed & \\
\hline
\end{tabular}
anchor pipe lengths; (c) the maximum pressure at the vault for different anchor pipe lengths; (d) the maximum stress in the $x$-direction for different anchor pipe lengths.

TABLE 4: Test sections. 


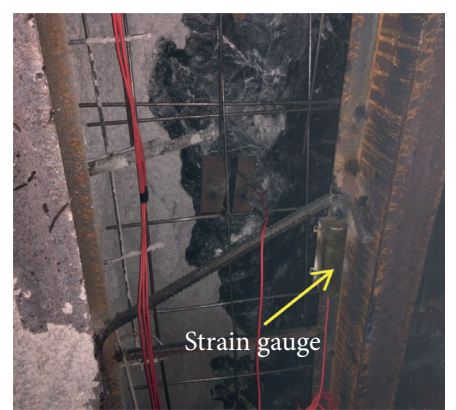

(a)

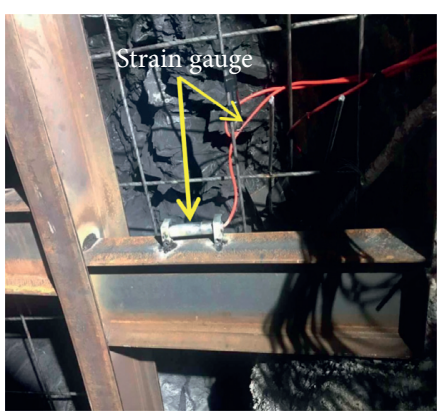

(b)

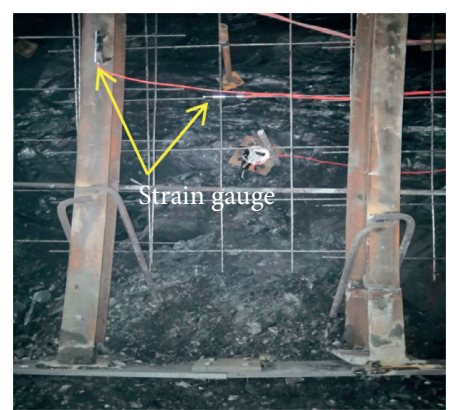

(c)

FIGURE 17: Instrument layout: (a) longitudinal connection of the rebar; (b) longitudinal connection of the channel steel; (c) new longitudinal connection system.

TABLE 5: Monitoring program.

\begin{tabular}{|c|c|c|c|c|}
\hline Test time & $1 \sim 15 \mathrm{~d}$ & $16 \mathrm{~d} \sim 1 \mathrm{~m}$ & $1 \sim 3 \mathrm{~m}$ & $>3 \mathrm{~m}$ \\
\hline Measurement frequency & $1-2$ times/d & 1 times $/ 2 \mathrm{~d}$ & $1 \sim 2$ times/w & $1 \sim 3$ times $/ \mathrm{m}$ \\
\hline
\end{tabular}

Note. $\mathrm{d}$ is day, and $\mathrm{m}$ is month.
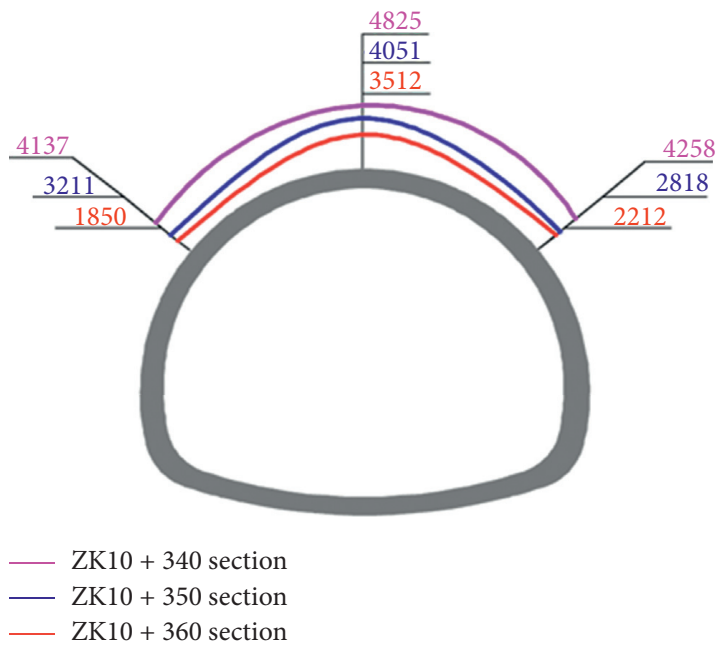

(a)

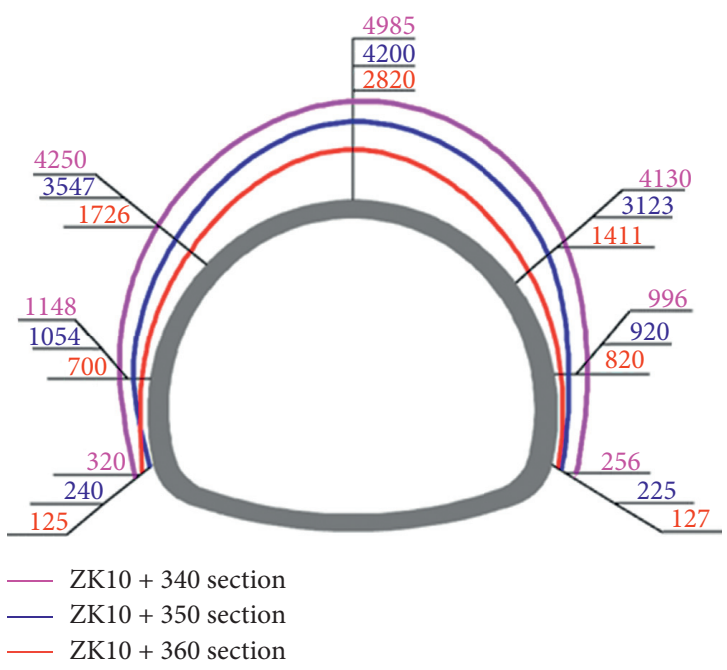

(c)
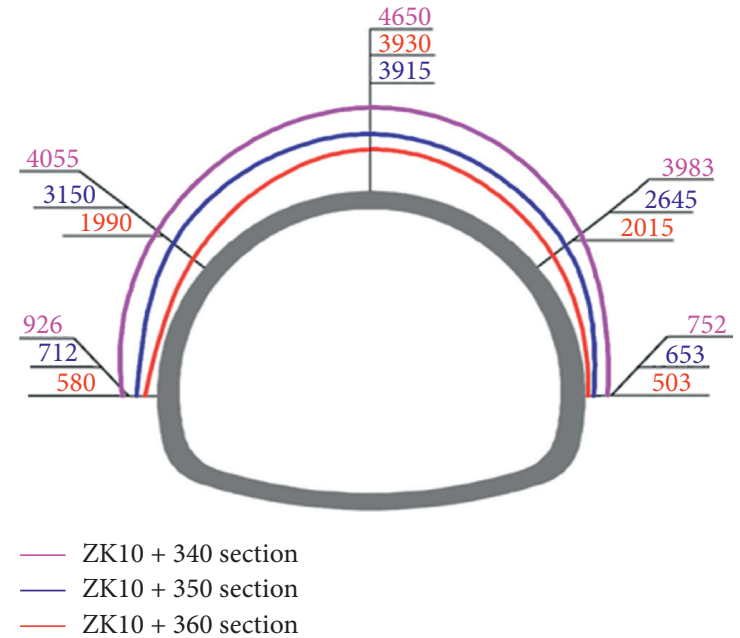

- ZK10 + 360 section

(b)

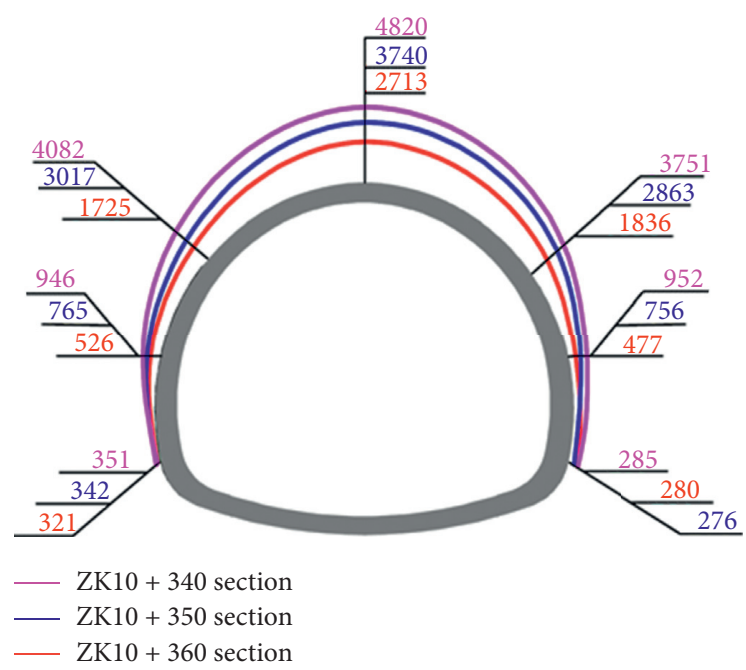

(d)

FIGURE 18: The strain of steel arch of three test sections: (a) after the upper step excavation (unit: $\mu \varepsilon$ ); (b) after the middle step excavation (unit: $\mu \varepsilon$ ); (c) after the lower step excavation (unit: $\mu \varepsilon$ ); (d) after stabilization (unit: $\mu \varepsilon$ ). 

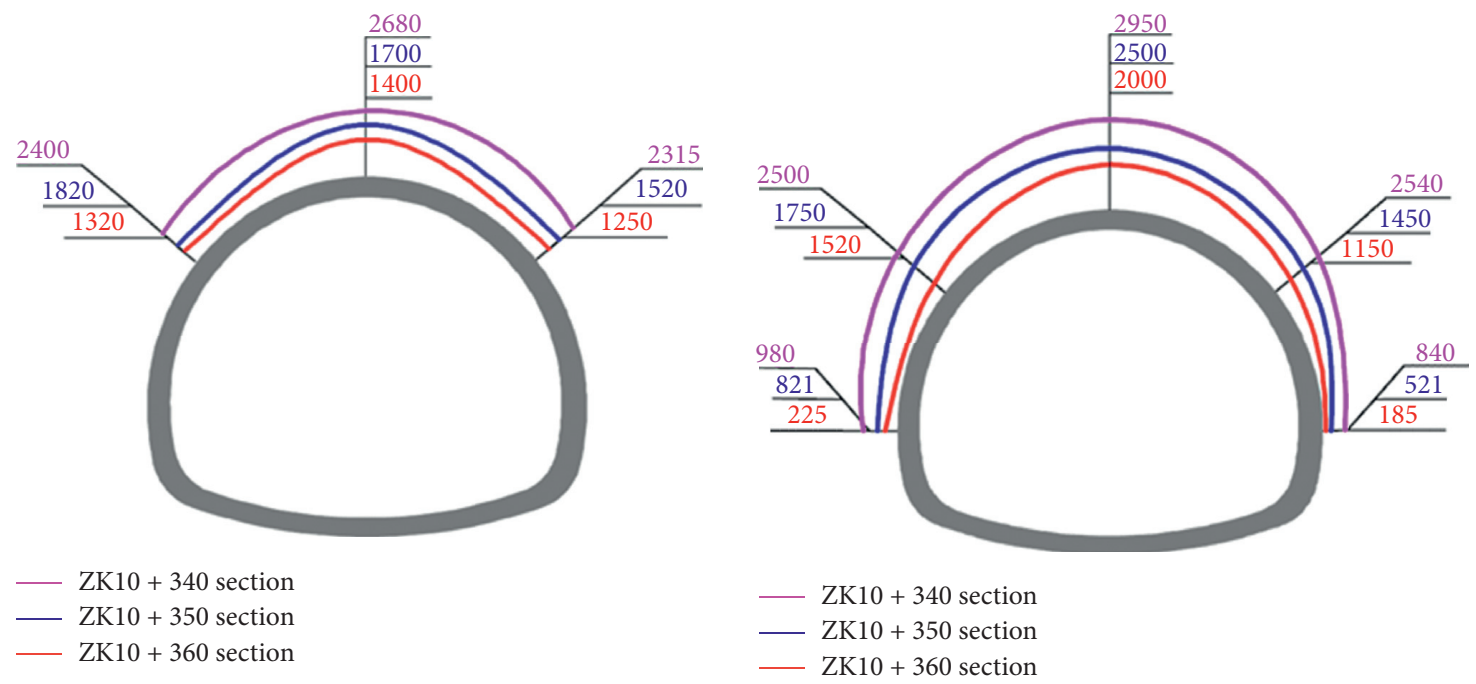

\section{(a)}

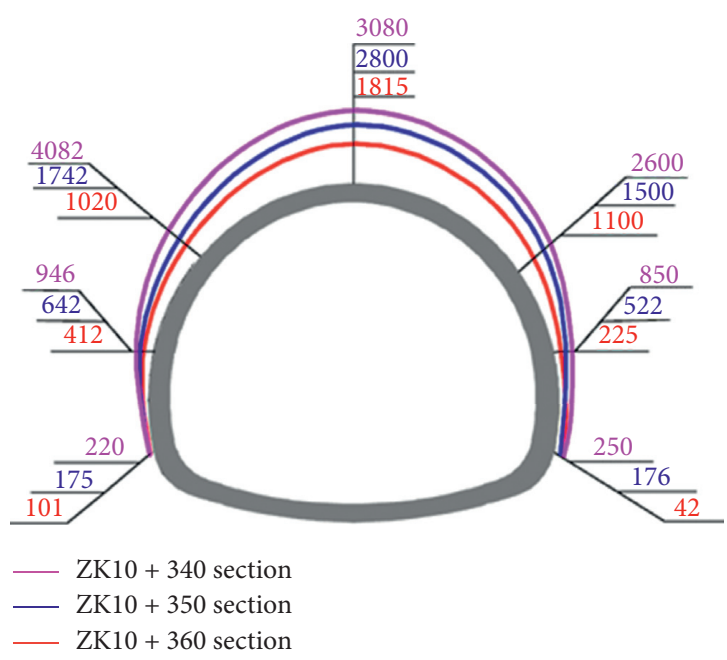

(c)

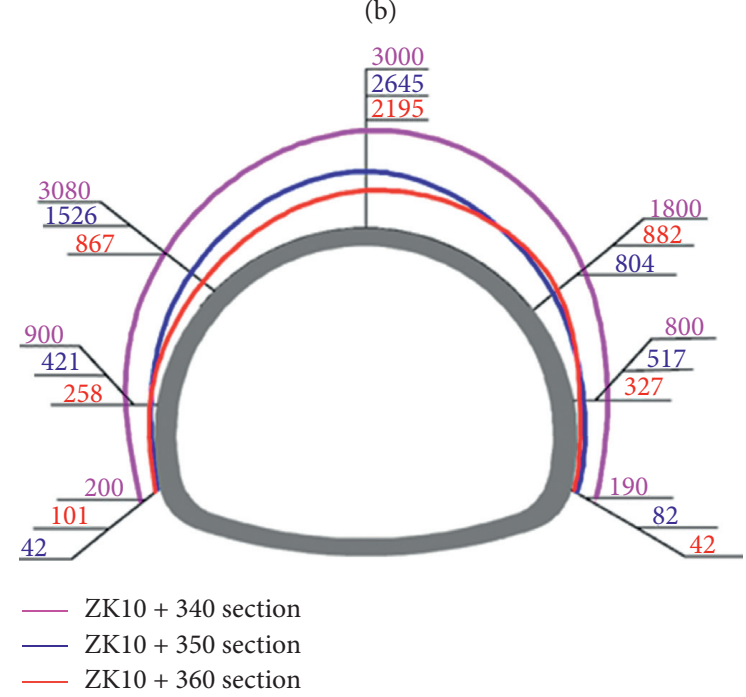

(d)

FIGURE 19: The strain of concrete of three test sections: (a) after the upper step excavation (unit: $\mu \varepsilon$ ); (b) after the middle step excavation (unit: $\mu \varepsilon$ ); (c) after the lower step excavation (unit: $\mu \varepsilon$ ); (d) after stabilization (unit: $\mu \varepsilon$ ).

(2) After the excavation of the upper and middle steps, the strain of the concrete in the three sections increases. After the lower step excavation, the strain in section 1 and section 2 increases, whereas that of section 3 decreases. After stabilization, the strain values of the concrete in the three sections are in the following order: section $1>$ section $2>$ section 3 .

(3) The vault settlement of section 1 stabilizes after about $30 \mathrm{~d}$, with a cumulative value of $43.3 \mathrm{~mm}$; that of section 2 stabilizes after about $10 \mathrm{~d}(28.6 \mathrm{~mm})$; that of section 3 stabilizes after about $5 \mathrm{~d}(13.5 \mathrm{~mm})$; and that of section 4 stabilizes after about $20 \mathrm{~d}(22.4 \mathrm{~mm})$. The vault settlement of section 3 is the fastest, and the cumulative value is the smallest; the stability period of the arch crown settlement of section 1 is the longest, and the cumulative value is the largest. The results show that, in terms of limiting the settlement of the tunnel vault, the order of the support measures is "the LREF" > "new longitudinal connection" > channel steel longitudinal connection + locking foot anchor" > "rebar longitudinal connection + locking foot anchor".

(4) The cumulative convergence of the upper step in section 1 is $19.5 \mathrm{~mm}$, that in section 2 is $7.0 \mathrm{~mm}$, that in section 3 is $3.8 \mathrm{~mm}$, and that in section 4 is $4.5 \mathrm{~mm}$. The fastest step convergence in section 3 is stabilizing first, and the slowest step convergence in section 1 is stabilizing last. In terms of the ability to limit the convergence around the tunnel, the order of the support measures is "the LREF" > "new 


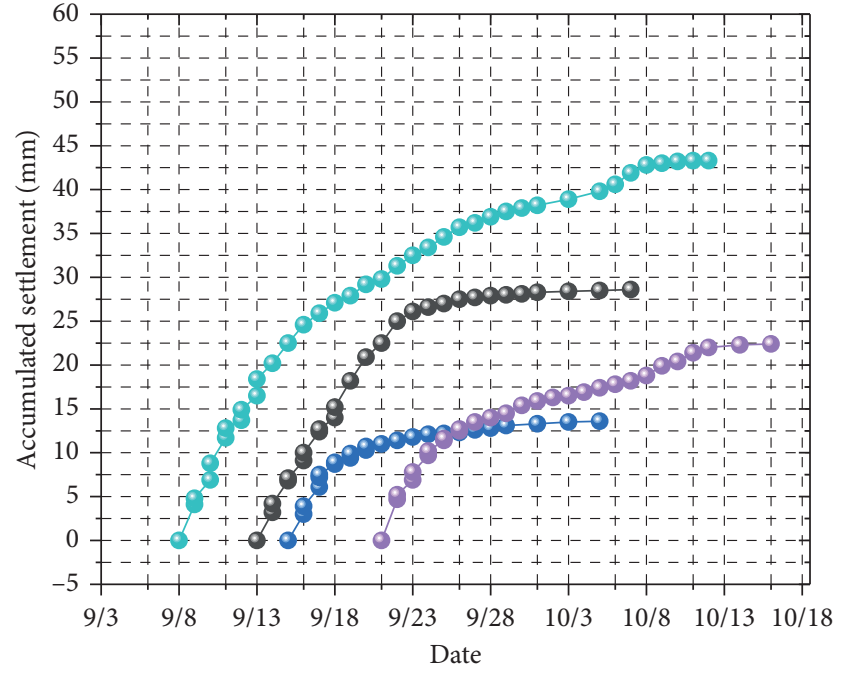

- $\mathrm{ZK}+10+340$ accumulated settlement

- $-\mathrm{ZK}+10+350$ accumulated settlement

-o- $Z K+10+360$ accumulated settlement

- $-\mathrm{ZK}+10+370$ accumulated settlement

Figure 20: Accumulated settlement of the vault in the four test sections.

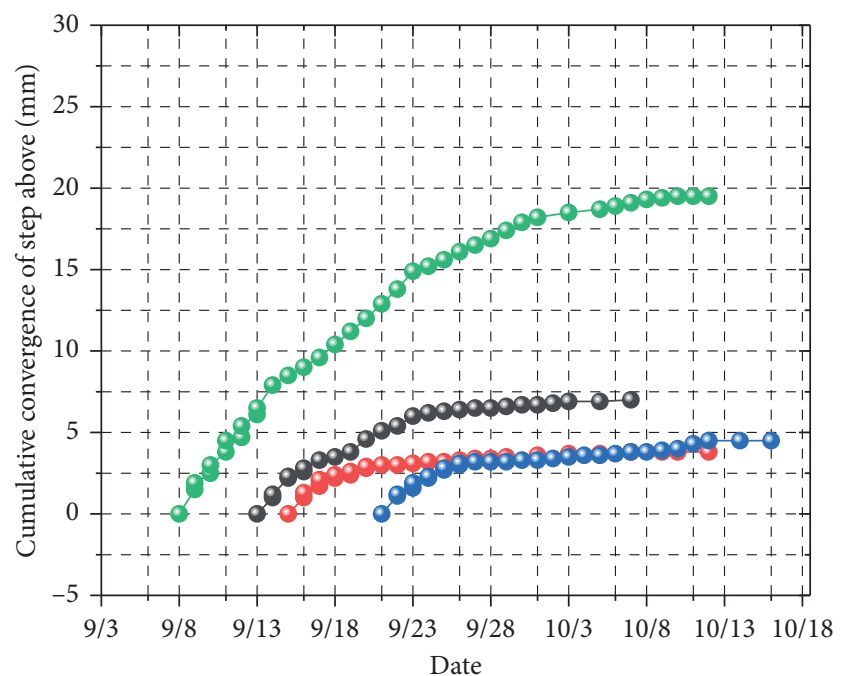

- $\mathrm{ZK} 10+340$ cumulative convergence
- $\mathrm{ZK} 10+350$ cumulative convergence
- $\mathrm{ZK} 10+360$ cumulative convergence
- $\mathrm{ZK} 10+370$ cumulative convergence

Figure 21: Cumulative convergence of the upper step in the four test sections.

longitudinal connection" > "channel steel longitudinal connection + locking foot anchor" > "rebar longitudinal connection + locking foot anchor."

The reasons for the results are as follows:

(1) The LREF has a higher strength and rigidity and can bear higher stress than the longitudinal connection with the rebar. The LREF has better longitudinal integrity than the longitudinal connection with the channel steel because the steel arches are connected in a straight line in the LREF, which ensures that the steel arches bear the force and deformation evenly.

(2) In construction, the connection of the hoop steel arch is the weak link in terms of stress, and the distortion of the steel arch often occurs first at this location. The LREF connects the steel arches using different steps, strengthens the connection between the ring steel arches, improves the circumferential bearing capacity of the steel arches, and reduces the damage to the joints caused by stress concentration.

(3) The longitudinal connection steel plate in the LREF has a certain transverse width. According to the structural design principle, the transverse reinforcement limits the development of longitudinal cracks, improves the bond strength of the concrete and the longitudinal connection steel plate, and increases the stress area of the concrete and the longitudinal connection steel plate. As a result, the stress is evenly distributed in the rigid expansion foundation, reducing the deformation of the support structure.

(4) After the excavation of the lower step of the tunnel, the steel arch will sink due to the weight, and displacement will occur due to uneven left and right forces. The setting of the anchor pipe can limit the rigid displacement of the steel arch, ensuring that the steel arch bears the pressure caused by surrounding rock deformation as fast as possible.

\section{Conclusion}

(1) We conducted a case study of a tunnel called Qiguding in Meizhou City, Guangdong Province, to investigate the deformation and stress characteristics of the carbonaceous mudstone tunnel. The following was observed: (1) the deformation and stress of the tunnel in the carbonaceous mudstone section are high, following the order vault $>$ waist $>$ sidewall $>$ arch foot; (2) the transverse and longitudinal deformation of the tunnel is unevenly distributed.

(2) The failure characteristics are used to analyze the deformation and failure mechanisms of the tunnel. It is observed that (1) the reasons for the failure are the soft characteristics and plastic rheology of the carbonaceous mudstone; (2) the carbonaceous mudstone tunnel has developed bedding and significant shear slip deformation.

(3) Through simulation and theoretical analysis, a new support measure is proposed, namely, the LREF, which includes a new longitudinal connection system and a locking foot anchor $\left(3.5 \mathrm{~m}, 35^{\circ}\right.$. The new support scheme is used in the construction of the Qiguding tunnel, and comparative tests are carried out. The following results are obtained: (1) the strains of the steel 
arch and concrete of the LREF of the tunnel are lower than that those of the ordinary steel longitudinal connection and the channel steel longitudinal connection; (2) when a locking anchor pipe is installed, the performance of the longitudinal connection modes in terms of the tunnel peripheral convergence and vault settlement is in the following order: LREF > channel steel longitudinal connection $>$ rebar longitudinal connection; and (3) the performance is improved when a locking foot anchor is installed.

\section{Data Availability}

The data used to support the findings of this study are available from the corresponding author upon request.

\section{Conflicts of Interest}

The authors declare that they have no conflicts of interest.

\section{Acknowledgments}

The authors gratefully acknowledge financial support from the Science and Technology Project of Guangdong Transportation Group, China.

\section{References}

[1] J. B. Fang, "Large deformation mechanics mechanism and rigid-gap-flexible-layer supporting technology of soft rock tunnel," China Journal of Highway and Transport, vol. 22, no. 6, pp. 90-95, 2009.

[2] L. Meng, T. Li, Y. Jiang, R. Wang, and Y. Li, "Characteristics and mechanisms of large deformation in the Zhegu mountain tunnel on the Sichuan-Tibet highway," Tunnelling and Underground Space Technology, vol. 37, pp. 157-164, 2013.

[3] X. Yang, J. Pang, D. Liu et al., "Deformation mechanism of roadways in deep soft rock at Hegang Xing'an coal mine," International Journal of Mining Science and Technology, vol. 23, no. 2, pp. 307-312, 2013.

[4] N. Zhang, J. Li, and P. Fan, "Computational method of large deformation and its application in deep mining tunnel," Tunnelling and Underground Space Technology, vol. 50, pp. 47-53, 2015.

[5] S. C. Li, Q. P. Wang, H. B. Wang et al., "Model test study on surrounding rock deformation and failure mechanisms of deep roadways with thick top coal," Tunnelling and Underground Space Technology, vol. 47, pp. 52-63, 2015.

[6] M. Huang, J. W. Zhan, C. S. Xu, and S. Jiang, "New creep constitutive model for soft rocks and its application in the prediction of time-dependent deformation in tunnels," International Journal of Geomechanics, vol. 20, no. 7, Article ID 04020096, 2020.

[7] J. Sun, Finite Element Analysis of Underground Structure, Tongji University Press, Shanghai, China, 1988.

[8] J. L. Lu, "Combined support method of permanent cavern in soft rock," Journal of Geotechnical Engineering, vol. 8, no. 5, pp. 50-57, 1986, in Chinese.

[9] M. C. He, H. H. Jing, and X. M. Sun, Engineering Mechanics of Soft Rock, Science Press, Beijing, China, 2002

[10] B. Meng, H. W. Jing, K. F. Chen, and H. J. Su, "Failure mechanism and stability control of a large section of very soft roadway surrounding rock shear slip," International Journal of Mining Science and Technology, vol. 23, no. 1, pp. 127-134, 2013.

[11] H. Kang, "Support technologies for deep and complex roadways in underground coal mines: a review," International Journal of Coal Science \& Technology, vol. 1, no. 3, pp. 261-277, 2014.

[12] J. Zuo, J. Wang, and Y. Jiang, "Macro/meso failure behavior of surrounding rock in deep roadway and its control technology," International Journal of Coal Science \& Technology, vol. 6, no. 3, pp. 301-319, 2019.

[13] H. T. Liu, "Research on lengthening bolt roof support system performance in largely deformed roadway," Journal of China Coal Society, vol. 39, no. 4, pp. 600-607, 2014.

[14] M. C. He, W. L. Gong, J. Wang et al., "Development of a novel energy-absorbing bolt with extraordinarily large elongation and constant resistance," International Journal of Rock Mechanics and Mining Sciences, vol. 67, pp. 29-42, 2014.

[15] Y. Y. Jiao, L. Song, X. Z. Wang, and A. Coffi Adoko, "Improvement of the U-shaped steel sets for supporting the roadways in loose thick coal seam," International Journal of Rock Mechanics and Mining Sciences, vol. 60, pp. 19-25, 2013.

[16] Q. Wang, R. Pan, B. Jiang et al., "Study on failure mechanism of roadway with soft rock in deep coal mine and confined concrete support system," Engineering Failure Analysis, vol. 81, pp. 155-177, 2017.

[17] H. Wang, W. Z. Chen, X. J. Tan, H. F. Tian, and J. J. Cao, "Development of a new type of foam concrete and its application on stability analysis of large-span soft rock tunnel," Journal of Central South University, vol. 19, no. 11, pp. 3305-3310, 2012.

[18] W. Z. Chen, H. M. Tian, F. D. Yang, and Y. M. Geng, "Study of effects of foam concrete preset deformation layer on longterm stability of deep soft rock tunnel," Rock Mechanics, vol. 032, no. 009, pp. 2577-2583, 2011.

[19] G. J. Wu, W. Z. Chen, H. F. Tian, S. P. Jia, J. P. Yang, and X. J. Tan, "Numerical evaluation of a yielding tunnel lining support system used in limiting large deformation in squeezing rock," Environmental Earth Sciences, vol. 77, no. 12, 2018.

[20] X. Y. Kong, X. Chen, C. A. Tang, Z. R. Sun, and E. H. Hu, "Study on large deformation control technology and engineering application of tunnel with high ground stress and weak broken surrounding rock," Structural Engineering International, 2020.

[21] X. Tan, W. Chen, H. Liu et al., "A combined supporting system based on foamed concrete and U-shaped steel for underground coal mine roadways undergoing large deformations," Tunnelling and Underground Space Technology, vol. 68, pp. 196-210, 2017.

[22] H. Wang, C. Jiang, P. Q. Zheng, W. J. Zhao, and N. Li, “A combined supporting system based on filled-wall method for semi coal-rock roadways with large deformations," Tunnelling and Underground Space Technology, vol. 99, 2020.

[23] Z. G. Tao, J. D. Cao, L. Yang et al., "Study on deformation mechanism and support measures of soft surrounding rock in muzhailing deep tunnel," Advances in Civil Engineering, vol. 2020, Article ID 9367916, 14 pages, 2020.

[24] L. Zeng, J. Liu, Q. F. Gao, and H. B. Bian, "Evolution characteristics of the cracks in the completely disintegrated carbonaceous mudstone subjected to cyclic wetting and drying," Advances in Civil Engineering, vol. 2019, Article ID 1279695, 10 pages, 2019. 
[25] X. X. Liu, S. N. Li, and Y. M. Zhou, "Research on the disintegration characteristics of carbonaceous mudstone and properties of modified materials," Advances in Civil Engineering, vol. 2019, Article ID 4382054, 10 pages, 2019.

[26] X. W. Chen, "Deformation test of pre-disintegrating carbonaceous mudstone under loading and foundering condition," Journal of Central South University (Science and Technology, vol. 50, no. 4, pp. 976-982, 2019.

[27] H. Fu, J. Liu, L. Zeng, L. Xiao, and P. Hou, "Disintegration characteristics of carbonaceous mudstone under loading and wet-dry cycles," China Journal of Highway and Transport, vol. 32, pp. 22-31, 2019. 